\title{
Otimização no processo de montagem de cilindro mestre de freio
}

\section{Optimization in the brake máster cylinder assembly process}

\author{
Rogério Greque Härter ${ }^{1 *}$, Ariane Ferreira Porto Rosa ${ }^{1}$, Eduardo Walker $^{1}$, Rogério Royer $^{1}$
}

\begin{abstract}
RESUMO
Este trabalho objetiva otimizar o processo de montagem de um cilindro mestre de freio. Cilindros mestres são responsáveis por fazer a frenagem de veículos automotores, os quais passam por vários processos e contemplam diversos componentes responsáveis pela sua funcionalidade. Deste modo, evidenciamos a importância que este produto apresenta para o mercado rodoviário. Através da aplicação do Método de Análise e Solução de Problemas e de diferentes ferramentas da qualidade foi possível obter um ganho de produtividade do produto estudado, que inicialmente se apresentava com produção hora de 33 peças e hoje tem um processo que garante produção hora de no mínimo 40 peças. Assim, consegue-se produzir o lote anual médio do item com 6 horas a menos de produção. Foi possível reveler a eficiência obtida no processo de montagem do item, relacionando com seu componente de vedação, de modo a não alterar a aplicabilidade do produto, mas aumentar a produção deste, garantindo a durabilidade do cilindro, tornando o item um produto de baixa complexidade e menor perda de montagem.
\end{abstract}

Palavras-chave: Cilindro mestre; Processo de montagem; Freio automotive; Sistema de freios.

\begin{abstract}
This work aims to optimize the assembly process of a brake master cylinder. Master cylinders are responsible for braking automotive vehicles, which go through various processes and include different components responsible for their functionality. In this way, we highlight the importance that this product has for the road market. Through the application of the Method of Analysis and Problem Solving and different quality tools, it was possible to obtain a gain in productivity of the product studied, which bulletin presented with an hourly production of 33 pieces and today has a process that guarantees production of a minimum of 40 hours. parts. Thus, it is possible to produce the average annual batch of the item with 6 hours less production. It was possible to reveal the efficiency obtained in the item assembly process, relating to its sealing component, so as not to change the applicability of the product, but to increase its production, ensuring the durability of the cylinder, making the item a low-complexity product and less assembly loss.
\end{abstract}

Keywords: Master cylinder; Assembly process; Automotive brake; Brake system.

\footnotetext{
${ }^{1}$ UFPel - Universidade Federal de Pelotas. *E-mail: rogerioharter@gmail.com
} 


\section{INTRODUÇÃO}

A história da indústria automobilística é marcada por um processo evolutivo extremamente acelerado, entretanto percebeu-se a necessidade de melhoria do transporte de cargas, principalmente no que se referia a sua própria locomoção. Pensando dessa forma, iniciou-se o processo de evolução no que tange aos transportes, desencadeando a utilização de animais para auxílio no carregamento destas mercadorias, podendo tomar como exemplo os cavalos, que desempenham muito bem essa função. Posteriormente, veio a descoberta da roda, cuja ferramenta recebe destaque, visto que aperfeiçoa mecanismos como o surgimento de carruagens, locomotivas e finalmente os automóveis (DNER, 1983).

Ao discorrer sobre carros, estamos falando de uma tecnologia de grande ascensão e que está presente na sociedade há alguns anos, especificamente no Brasil os automóveis estão presentes desde o século 19, com Henrique Santos Dumont, e em seguida a participação de grandes montadoras como Ford em 1919 e General Motors em 1925, atuando no mercado de importação de veículos, e esta importação criou ainda mais forças após a segunda guerra mundial (LIMA, 2017).

Seguindo essa linha de crescimento, o prefeito de São Paulo, Washigton Luís, o qual se encontrava na gestão neste marco do período, assim como o Presidente do Brasil da época, iniciam a campanha: "Governar é abrir estradas", o que se tornou meta para os governadores seguintes. Dessa forma, a maior preocupação destes líderes foi a construção de estradas, projetos que cresciam ano a ano. Consequentemente, os acidentes começavam a ocupar as manchetes dos jornais, e a população começou a pagar pelos benefícios da motorização e ainda não estava preparada para utilizá-lo com segurança, porém o automóvel se fez necessário passando a integrar a vida do homem como meio de trabalho, de entretenimento, tornando-se um objeto de desejo e de consumo (NASCIMENTO, 2016).

A partir desse aumento desenfreado e crescimento na área automobilística, em 1956 houve a criação do GEIA, criada por lei, cujo grupo surgia por objetivos estratégicos e para centralizar todas as demandas que esse setor passaria a necessitar, assim como a possibilidade de estar fabricando os veículos e não apenas montar, como estava sendo realizado no Brasil, fomentando assim a indústria siderúrgica do país (VIANINI, 2016). 
Consequentemente essa alta demanda gerou necessidade de melhoria dos automóveis, principalmente no que diz respeito ao sistema de freios, os quais ao entrarem no mercado recebiam modelos bastante rústicos e grosseiros, o que impossibilitava a garantia de segurança, e então surgiram diversos modelos que aprimoraram o sistema veicular, chegando a um sistema que encontramos hoje apresentando vários componentes, e diferentes funcionalidades dentro deste conjunto, buscando garantir a frenagem do veículo de forma ágil (DIULGHEROGLO, 2010).

O estudo deste trabalho está focado em escalonar um sistema de freios, buscando compreender um de seus componentes, podendo evidenciar a importância de um componente central do sistema e que sem ele, não existiria a frenagem do automóvel de forma tão simples e dinâmica, e toda sua funcionalidade se dá através da correta combinação de parâmetros e fatores do conjunto de componentes que nele se integram (BISOL, 2021).

Cilindros hidráulicos comandam o mercado quando se trata de freios, sendo um dos responsáveis pelo crescimento de $6 \%$ do mercado de reposição automotivo no ano de 2020 (NOVO VAREJO, 2020).

Tomando esses dados como base, destaca-se a grande importância da validação de qualquer mudança que pode ou não interferir no principal componente responsável pela frenagem de um veículo. Desta forma, busca-se com este trabalho o detalhamento para toda a elaboração do cilindro mestre de freio, onde serão pontuados todos os processos que o envolvem, até que o mesmo possa ser liberado ao cliente final, garantindo que este atenda suas funcionalidades.

Neste trabalho será pontuado todo o conjunto de atividades necessário para o pleno funcionamento do sistema em estudo. Serão apresentadas as análises dos processos em busca de otimização e redução de custos na produção do cilindro mestre de freio. Em específico será apresentado o estudo realizado na linha de montagem onde se almeja ganhos como facilidade de montagem e mão de obra direta. Busca-se que a organização possa contar com qualquer colaborador do seu quadro efetivo sem restrições de gênero, que atualmente ocorre devido à necessidade de maior força em uma etapa específica do processo de montagem do cilindro mestre de freio.

Assim, a problemática de pesquisa deste trabalho é: Como otimizar oprocesso de montagem de um cilindro mestre de freio em uma empresa de autopeças, de forma que 
acarrete na diminuição de custos, garantindo a funcionalidade e aplicabilidade do produto, juntamente com a melhoria ergonômica do processo?

Embora o método de pesquisa proposto neste trabalho possa ser aplicada em outros produtos similares da empresa automotiva, o estudo de caso realizado é único com foco em um produto e, portanto, os resultados obtidos delimitam-se ao escopo deste trabalho específico e que fortalece o método e suas ferramentas quando aplicado a indústria no geral, de modo a validar ganhos quando seguidos suas etapas precisamente.

O artigo está estruturado iniciando-se com a presente seção Introdução que delimita o escopo do trabalho desenvolvido. A seção 2 intitulada Referencial Teórico apresentaos conceitos dos principais assuntos teóricos como métodos, ferramentas qualidade e de melhoria de processo. Na seção 3 Metodologia é apresentada a classificação da pesquisa e a proposta a aplicação do método MASP-PDCA no estudo de caso, conforme os passos da Figura 1. A seção 4 trata do estudo de caso apresentando suas etapas e aplicação da metodologia proposta. Na seção 5 são apresentados os resultados obtidos no estudo de caso. A seção 6 apresenta as contribuições do trabalho para a indústria e sociedade. A seção 7 conclusões e sugestões de trabalhos futuros.

\section{REFERENCIAL TEÓRICO}

A revisão teórica busca introduzir conceitos sobre o sistema de frenagem de veículos, onde serão apresentadas as definições gerais sobre tais sistemas e componentes. Os pontos levantados buscam passar maior entendimento sobre o assunto e detalhar todas as escolhas feitas durante a realização deste trabalho. Para isso, são apresentados métodos e ferramentas de engenharia de produção, adequados para auxiliar nas decisões e realização deste estudo.

\subsection{Mapeamento de processos}

Ao observarmos o grande desenvolvimento do mercado nos dias de hoje, passamos a encontrar empresas focadas na competitividade, e a fim de obter um bom desempenho neste aspecto, estas optam por buscar a melhoria de seus processos, produto e/ou serviços, e para isso se abastecem de diversas técnicas e ferramentas para o alcance da otimização, podendo ser de um setor ou então da organização de modo geral (CANO, 2006). 
Segundo Deming (1986), as organizações devem estar continuamente em busca de melhoria de seus processos e produtos, ou seja, tudo que interfira em seus sistemas de produção. O objetivo principal é a melhoria de pontos como qualidade e produtividade, colocando sempre em primeiro plano a busca pela redução de custos.

\subsection{Métodos e ferramentas de otimização de processo}

A seguir são descritas algumas das principais metodologias de melhoria dos processos que foram aplicadas no estudo de caso proposto.

\subsubsection{Brainstorming}

O Brainstorming é bastante simples, significa "tempestade de ideias", tal termo criado por Alex Osborn, considerado seu criador em 1953. Refere-se de uma técnica com característica de simplicidade e de uso por qualquer área de conhecimento (ALVES, 2009).

È uma técnica que busca juntar pessoas e fomentar a criação de melhorias através da disposição de diferentes ideias, que podem ou não ter vínculo a um problema. Contudo o uso desta técnica buscará despertar a criatividade e assim acarretar em mudanças e levando em consideração diversas formas de pensamentos (SANTO, 2015).

\subsubsection{Diagrama Causa e Efeito}

O Diagrama de Causa e Efeito é utilizado para apresentar a relação existente entre um resultado de um processo (efeito) e os fatores (causas) do processo que possam afetar o resultado considerado, sendo de um problema ou uma suituação.

Com ele é possível estruturar causas de uma falha ou problema, ou ate mesmo uma oportunidade de melhoria e toda a cadeia de efeitos sob a qualidade. Dando um retorno de forma gráfica e sintética, além de ser tipicamente utilizado em sessões de brainstorming (TERNER, 2008). 


\subsubsection{Matriz de decisão}

A matriz de decisão é utilizada para facilitar o processo de decisão. Permite avaliar pontos fracos e fortes frente ao ponto de análise, proporcionando definir um plano de ação que concorde com cada problema identificado. Em uma tabela são elencados os pontos de avaliação e definido uma pontuação para estes pontos. Os pontos elencados na tabela são avaliados ou pontuados frente a um problema e assim chegamos a uma nota final para cada proposta de melhoria, o que vai fornecer um ranqueamento e facilitar para as decisões seguintes (UNESP, 2021).

\subsubsection{Matriz GUT}

A matriz GUT (Gravidade, Urgência e Tendência) é a maneira de ranquear quesitos mais importantes, baseados em medidas. Onde cada letra indicada na ferramenta tem um significado, sendo "G" a gravidade do problema, indicando o custo de não tratar o problema. "U" é a letra que se refere à urgência do problema, e trata-se do tempo disponível para tratá-lo. Por último, a letra "T" é a tendência do problema, onde demonstrara no que pode acarretar se nada for feito para resolver tal problema (SCARTEZINI, 2009).

Com as notas atribuídas, deve-se realizar o produto de todas as notas obtidas. $\mathrm{O}$ problema que obter maior nota será priorizado (SCARTEZINI, 2009).

\subsubsection{Plano de Ação 5W2H}

O plano de ação 5W2H foi elaborado no ramo automobilístico, por profissionais do Japão, onde se buscou estar auxiliando na utilização da ferramenta de qualidade PDCA (SILVA et al., 2013). Um plano de ação se faz fundamental para que haja o planejamento capaz de monitorar diferentes ações que deverão ser aplicadas. Sendo assim permite o acompanhamento de todo o desenvolvimento do projeto aplicado. Desta forma deve-se verificar e estruturar o plano de modo que se consiga identificação rápida de todos os aspectos necessários (OLIVEIRA, 1996).

$\mathrm{O}$ plano de ação5W2H deve evidenciar todas as atividades que precisam ser apuradas e desenvolvidas com a maior clareza possível para obter o entendimento do 
funcionário que irá colocá-la em prática. Ela tem como objetivo responder a sete questões simples e assim planejá-las de forma eficiente (MEIRA, 2003).

\subsection{Método de Análise e Solução de Problemas}

O Método de Análise e Solução de Problemas (MASP) tem o objetivo de trazer maior racionalidade e otimização, buscando seguir caminhos já definidos e que serão baseados em dados e fatos, que trarão maiores benefícios e menores esforços. É um método bastante prático e simples, que irá evidenciar causas e propor soluções dos problemas em análise de uma organização através de um plano de ação. Este método consiste em uma sequência de etapas que levam a um planejamento participativo para a melhoria da qualidade de um produto ou serviço de um determinado processo em uma organização.

Estas etapas do método MASP podem ser enquadradas dentro da metodologia do ciclo PDCA, conforme ilustrado nas divisões descritas na Figura 1.

Figura 1 - Ciclo de etapas do MASP

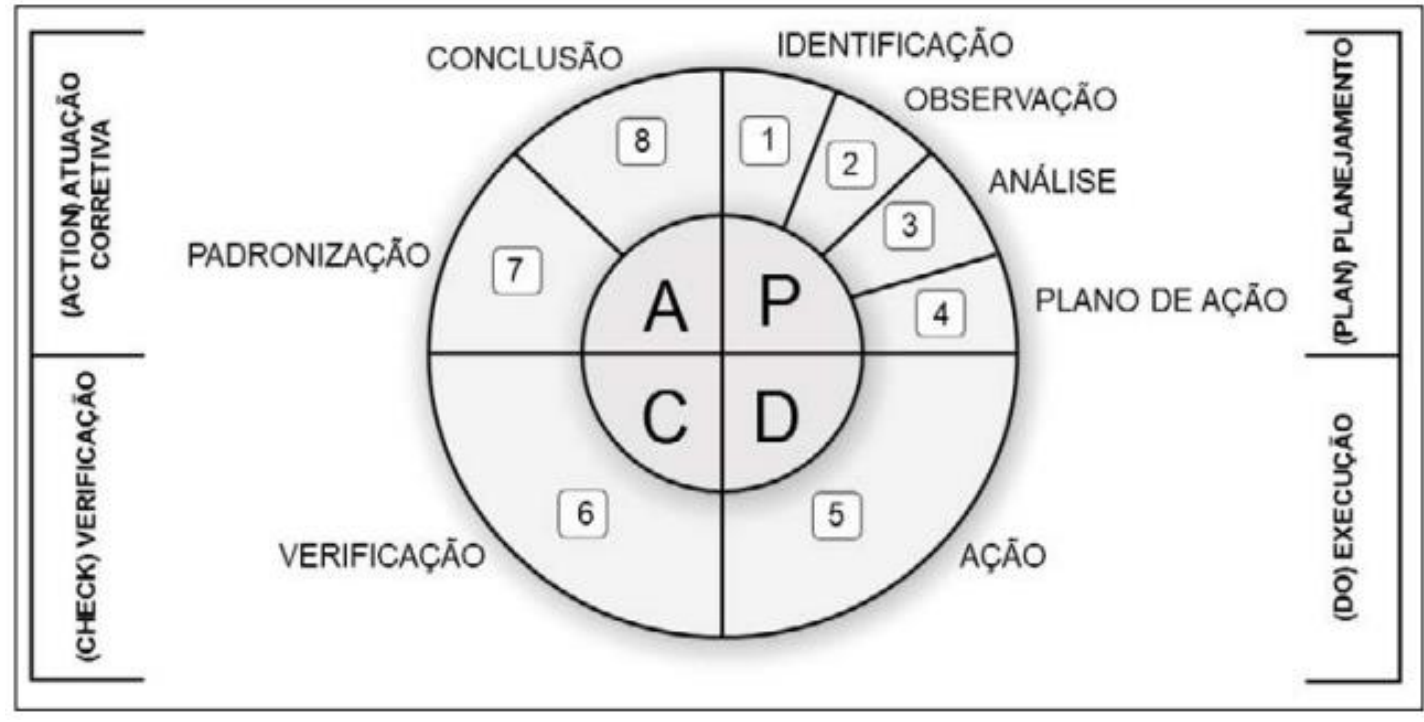

Fonte: Lorenzon (2019).

Alguns estudos da literatura apresentam aplicações da metodologia MASPPDCA em processos produtivos. Lobo e Loss (2017) apresentam a utilização das ferramentas do MASP para aumento de produtividade de máquina de Corte e Dobra. Os autores buscaram resolver o problema da baixaprodutividade em uma máquina de Corte e Dobra, utilizando para isso o método do MASP e as ferramentas da Qualidade. Fizeram uma análise dasprincipais causas para esta improdutividade utilizando-se o 
Diagrama de Pareto e em seguida são analisados os problemas relacionados a essas causascom a ajuda do Ishikawa. São mostrados os parâmetros de produtividade, antes de o trabalho ser iniciado, e depois de algumas ações sugeridas serem implementadas, novas verificações são feitas. $\mathrm{O}$ aumento nos números deprodutividade serve para comprovar que a aplicação das ferramentas gerouresultado.

Pessoa (2018) propôs a aplicação do método MASP num processo de repintura automotiva. Neste trabalho o problema de sobras de material na operação de acabamento foi solucionado, assim evitando desperdícios, melhorando e padronizando as atividades da mencionada operação. Braga e Borges (2019) utilizaram o método MASP em um estudo de caso em uma indústria do setor de autopeças automotivas. Júnior e Pacheco (2019) obtiveram a redução de custos com refugo em uma fábrica de embreagens através da aplicação do método MASP. Segundo os autores, foi possível eliminar as causas que impactavam diretamente nos custos do refugo eretrabalho estudado. Como resultado nos primeiros seis meses subsequentes a implementação dasações os custos foram reduzidos 95,32\% (valores superiores a ordem de $\mathrm{R} \$ 30.000,00)$, justificando assim a eficácia das ações propostas pela pesquisa.

Gayão e Bazante (2019) aplicaram o método MASP para a solução de problemas de reprocessamento de embalagens de água sanitária. Segundo os autores, a empresa tinha uma elevada taxa de reprocesso de garrafas, devido a problemas na produção das mesmas. A implantação do Método de Análise e Solução de Problemas, junto com a aplicação das ferramentas da qualidade que são parte deste método, tornou possível identificar e solucionar os problemas, estabilizando a taxa de reprocesso das embalagens, e atingindo a sistemática da melhoria contínua nos processos e produtos oferecidos para o consumidor final.

\subsection{Objeto de estudo de caso: Cilindro mestre de Freio}

Em geral o sistema de frenagem é composto por um conjunto de itens que possuem a finalidade de desacelerar ou parar completamente um veículo. Este estudo está focado no processo de montagem do cilindro mestre de freio, que é um dos itens de segurança mais importantes de qualquer veículo.

Segundo Mesquita (2017), o cilindro mestre é o componente capaz de fornecer pressão hidráulica para que os freios nas rodas sejam acionados, toda esta pressão 
gerada com o auxílio do fluido de freio que vai mais especificamente até as pinças ou cilindros de rodas. É um item fundamental para todo o sistema, podendo ser considerado o "coração" de todo esse conjunto para que o freio funcione corretamente. Quando o condutor aciona o pedal de freio por meio de uma haste chamada de pushrod, do qual acaba acionando o servo freio que aumenta a força para que haja o acionamento do cilindro mestre, sendo através desse funcionamento que o líquido de freio é jogado para fora, fazendo circular no sistema para que exista a frenagem (NETO, 2018).

Nas aplicações atuais, podemos encontrar cilindros mestres de câmara simples e câmara dupla (veículos mais novos), que veio para sanar problemas que no modelo simples apresenta. Ambos os modelos encontrados possuem funções como a conservação da pressão residual de todo o sistema; a compensação de aumento do volume do fluido de reservatório e; não permitir a geração de depressão no sistema de frenagem (SANTOS, 2014).

A Figura 2 ilustra o produto de análise neste estudo de caso.

Figura 2 - Cilindro mestre de freio estudado

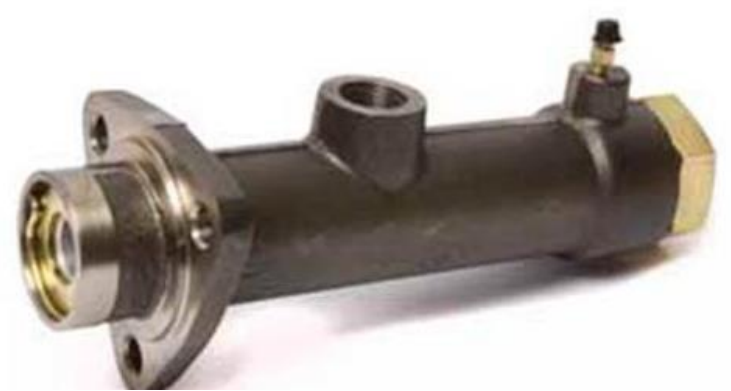

Fonte: Catálogo da empresa (2021).

\subsubsection{Vedações de sistemas de freio}

Para pleno funcionamento de um sistema de freios, necessitamos contar com modelos diversos de vedações, principalmente se referindo a formatos e dimensões. Contudo no que se refere à composição deste modo de vedação, o mais comum se trata da borracha de etileno-propileno-dieno (EPDM), da qual se refere à borracha que faz parte do grupo de "borrachas de etileno-propileno" que contém copolímeros e terpolímeros. O uso de EPDM se dá em sistemas hidráulicos que usam líquidos não inflamáveis à base de fosfato orgânico. A vedação EPDM está presente na indústria automotiva, na indústria de caixilharia e em outras indústrias de segmentos parecidos, já 
que possuem propriedades que garantem vedação quando acopladas em circuitos que levam líquido para sua manipulação (GENERAL SEAL, 2021).

As vedações segundo General Seal (2021), das quais estão inseridas nos sistemas de freios, uso que se dá pelo motivo das vedações em EPDM garantirem as seguintes propriedades: resistência ao ozona e ao tempo, resistência térmica, boa deformação permanente, flexibilidade a baixas temperaturas $\left(-95^{\circ} \mathrm{C}\right)$, excelentes propriedades de isolação elétrica e alta impermeabilidade a água e gases.

Entre os formatos utilizados para estas vedações, podem ser encontrados os anéis oring, que se caracterizam pelo perfil de seção transversal em forma de círculo, ou seja, tem o formato de "O" e são utilizados na vedação ou junção de equipamentos. O respectivo anel se trata de um item simples e versátil, o que torna a instalação rápida e de baixo custo.

Além disso, em casos específicos, encontraremos vedações em metal, principalmente de cobre, usadas para garantir maior resistência. Entretanto, este tipo de vedação em metal dependerá de uma força de atrito maior sobre a superfície de vedação.

\section{MÉTODO DE PESQUISA}

Inicialmente foi realizada uma pesquisa bibliográfica em livros, artigos e sites contendo informações sobre a proposta do tema, com o intuito de trazer esclarecimentos e fundamentar a pesquisa. Sendo assim, utilizou-se de acordo com os objetivos específicos do trabalho, uma pesquisa fundamentada em um estudo de revisão bibliográfica sobre o tema proposto para que haja o suprimento de conhecimento a todos que terão acesso a este trabalho.

De acordo com os objetivos, utilizou-se uma pesquisa exploratória, que para Gil (2008) é elaborada com o propósito de proporcionar uma visão geral, de caráter aproximativo, a respeito de determinado fato que ao final do processo, torna-se um problema compreensível, susceptível de investigação mediante uma sistematização de alguns procedimentos.

Quanto à classificação, pode se dizer que é também uma pesquisa aplicada, tendo como objetivo produzir conhecimento para a aplicação prática, voltado para solução específicas de problemas. A partir da aplicação do projeto em estudo se 
considera como uma pesquisa de classe quantitativa, pois permite tudo ser mensurável, onde traduz em números e categorias, para serem feitas as devidas análises (GIL, 2008).

Com relação à escolha da modalidade de pesquisa tem-se neste projeto um estudo de caso, que segundo Fachin (2006), se caracteriza por um estudo intensivo, onde se leva em conta a compreensão do assunto como um todo, do assunto investigado.

Para a realização do estudo de caso foram seguidos os passos sequenciais do método MASP - PDCA conforme ilustrado na Figura 1. Buscou-se aplicar no estudo de caso as principais metodologias de melhoria dos processos, citadas na seção referencial histórico, nas etapas apropriadas do método MASP-PDCA, fortalecendo a teoria que se possui com relação a esta metodologia, evidenciando sua assertividade.

\section{ESTUDO DE CASO}

Aorganização é dividida em quatro grandes setores de produção, três deles responsáveis pela transformação de materiais, possibilitando ao quarto setor reunir tais componentes e possibilitar a montagem de um produto final, que se trata de um cilindro mestre de freio. A escolha pelo processo e produto deste estudo de caso, se deu pelo fato deste item apresentar muitas falhas, grandes esforçose ruídos elevados gerados em etapa específica de montagem.

Além disso, há necessidade de operadores bem treinados e que possam garantir maiores condições físicas para suportar o produto de maior peso que a empresa produz. Assim como a manipulação de maquinário de montagem pesado.

O quadro 1 apresenta as 11 operações de montagem necessárias. Estas operações sequenciadas corretamente geram um produto acabado a cada 110 segundos. A operação 2 necessita de 30 segundos para ser concluída e após o produto pode ser liberado para as demais operações. As operações são sequenciadas e ocorrem em fluxo contínuo, o que gera uma produção de 33 peças por hora. Esta taxa de produção não considera a taxa de reprovação (retrabalho) de 18,35\%. A taxa de reprovação foi fornecida pelo sistema ERP da empresa, referente a toda a produção do ano de 2020. 
Quadro 1- Fluxo de operações do produto.

\begin{tabular}{|c|l|}
\hline Operação & Descrição \\
\hline $\mathbf{1}$ & Montagem da válvula no parafuso sextavado \\
\hline $\mathbf{2}$ & Colocação do sextavado na carcaça \\
\hline $\mathbf{3}$ & Colocação da mola \\
\hline $\mathbf{4}$ & Colocação da gaxeta de pressão \\
\hline $\mathbf{5}$ & Colocação do pistão \\
\hline $\mathbf{6}$ & Grampo de fechamento do produto \\
\hline $\mathbf{7}$ & Colocação do parafuso sangrador \\
\hline $\mathbf{8}$ & Colocação na máquina de teste \\
\hline $\mathbf{9}$ & Aprovado, colocar no berço de gravação de rastreamento \\
\hline $\mathbf{1 1}$ & Colocar protetor do parafuso sangrador \\
\hline
\end{tabular}

Fonte: Autores (2021).

A Figura 3 apresenta os componentes utilizados e suas respectivas acomodações, formando o produto final, onde podemos observar o item "Sextavado montado" e a vedação “AN-6/205”, responsáveis pelas perdasde montagem e falhas no produto.

Figura 3- Desenho 2D do produto montado e seus componentes.

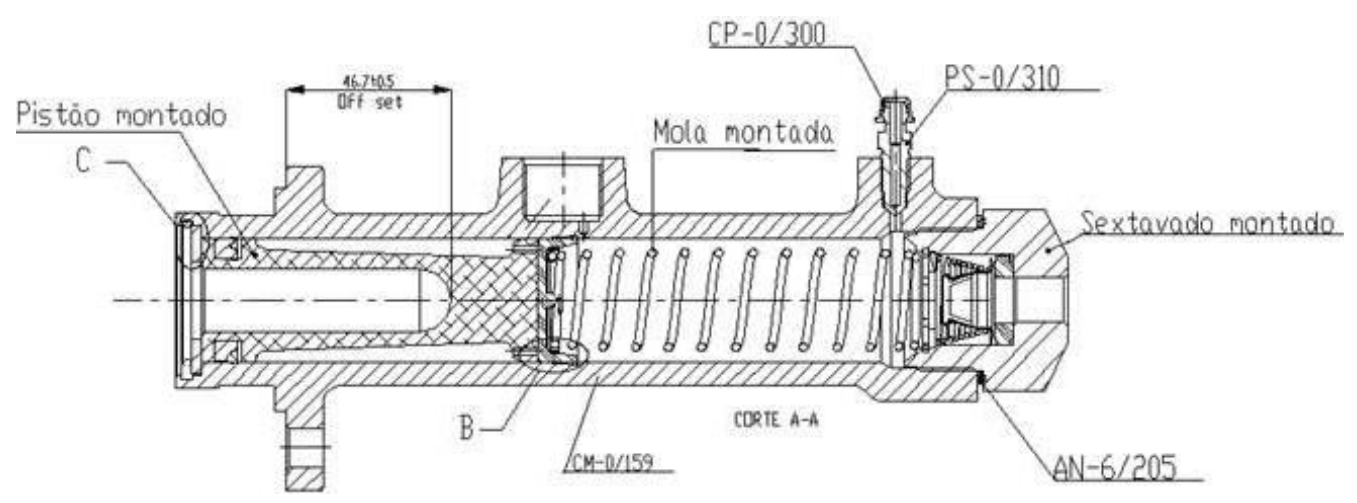

Fonte: Sistema da organização (2021).

A maioria das operações é manual, onde a dependência por equipamentos se dará para 3 das 11 operações encontradas. A operação 2 é importante para que não haja perda de produção e/ou retrabalho aplicados ao produto. As demais operações acabam sendo operações padronizadas e de parâmetros constantes, ou seja, acabam não tendo influência direta no tempo de ciclo de montagem.

Assim,o processo de montagem é complexo, de baixa produtividade, já que a empresa em sua maioria possui produtos com produção hora na média de 65 peças, e com índice de reprovação inferior ao deste produto de estudo. 


\subsection{Identificação do problema}

A montagem do cilindro em estudo tem consequências indesejáveis para a organização, já que o produto acaba sendo uma das peças com maior peso e maior custo para a organização. $O$ processo de montagem dos componentes, conforme o sequenciamento de etapas descritas no Quadro 1, ocorre por dois operadores. O primeiro operador realiza a pré-montagem, que se trata da colocação e montagem de todos os componentes internos do cilindro. O segundo operador encarrega-se de fazer o fechamento final do produto, colocá-lo na máquina de teste e por fim fazer gravação e embalagem do produto. A etapa de fechamento final exige força física para manuseio do maquinário, então este segundo operador deve ser obrigatoriamente homem.

O produto apresenta problemas por taxas de reprovações devido a não conformidade indicada na máquina de testes. A máquina faz a vedação pneumática de todas as saídas abertas do produto e aplica 6000 mbar no seu interior, o produto não deve apresentar vazamentos superiores a 20 mbar em 3 segundos, caso contrário há reprovação da unidade.

Os testes na máquina de vedação pneumática evidenciam a baixa produtividade, que é ocasionada principalmente pelo vazamento entre o "anel de vedação carcaça $\mathrm{x}$ sextavado". Omaterial utilizado no início deste estudo tratava-se de um anel de cobre, com a dureza especificada em projeto e com exigência de torque de $750 \mathrm{Nm}$ para que houvesse a vedação com o atrito entre as peças. No processo de aperto, era necessário o uso de uma parafusadeira de impacto.

\subsection{Definir o problema}

Identificou-se a necessidade de ação de contenção para minimizar o impacto desta perda devido à má vedação e a complexidade que tínhamos no processo devido à alta atenção sobre a fixação deste sextavado a carcaça. A análise do sequenciamento das operações de montagem do produto permitiu a reflexão sobre as oportunidades possíveis para aperfeiçoar o produto e o respectivo processo. De modo a conter vazamentos, inicialmente foi proposta a adição de uma operação sob o anel de cobre, um processo de recozimento. O objetivo foi tornar o anel de cobre mais flexível e 
maleável, de modo que se possa ter menor exigência de torque e uma melhorpossibilidade de vedação, até que fosse possível um estudo mais completo.

A Tabela 1 apresenta dos dados de produção do produto em 2020 obtidos do sistema ERP da empresa, associado aos relatórios de produção do produto, onde são pontuados todos os problemas encontrados na produção de um lote em especifico. Dados estes unificados e utilizados para análise deste estudo.

Tabela 1 - Dados de produção do produto

\begin{tabular}{l|c|c|c|c}
\hline \multirow{2}{*}{2020} & Lote & Quantidade & Reprovações & Devido anel de vedação \\
\cline { 2 - 5 } & 1 & 500 peças & 98 peças & 64 peças \\
\cline { 2 - 5 } & 2 & 595 peças & 103 peças & 68 peças \\
\hline \multicolumn{2}{c|}{ Total } & 1095 peças & 201 peças & 132 peças \\
\hline
\end{tabular}

Fonte: ERP da organização, (2021).

A partir da adição da operação de recozimento do anel de cobre, observou-se a necessidade de colocar um anel de maior vedação e de menor complexidade de aperto para buscar eliminar o problema de reprovação das peças por vazamento. Sendo assim, junto ao engenheiro de produto, foram propostos testes entre outros anéis de vedação o que resultou na busca pela substituição do anel de cobre por um anel de polímero, componente este bastante similar a outras vedações existentes em todo o sistema de freios de um veículo.

\subsection{Analisar o problema}

Foi elaborado um diagrama de causa e efeito, ilustrado na Figura 4, de modo a rastrear possíveis causa raízes presentes no processo e produto capazes de gerar a baixa produtividade do produto. 
Figura 4 -Diagrama de Causa e efeito

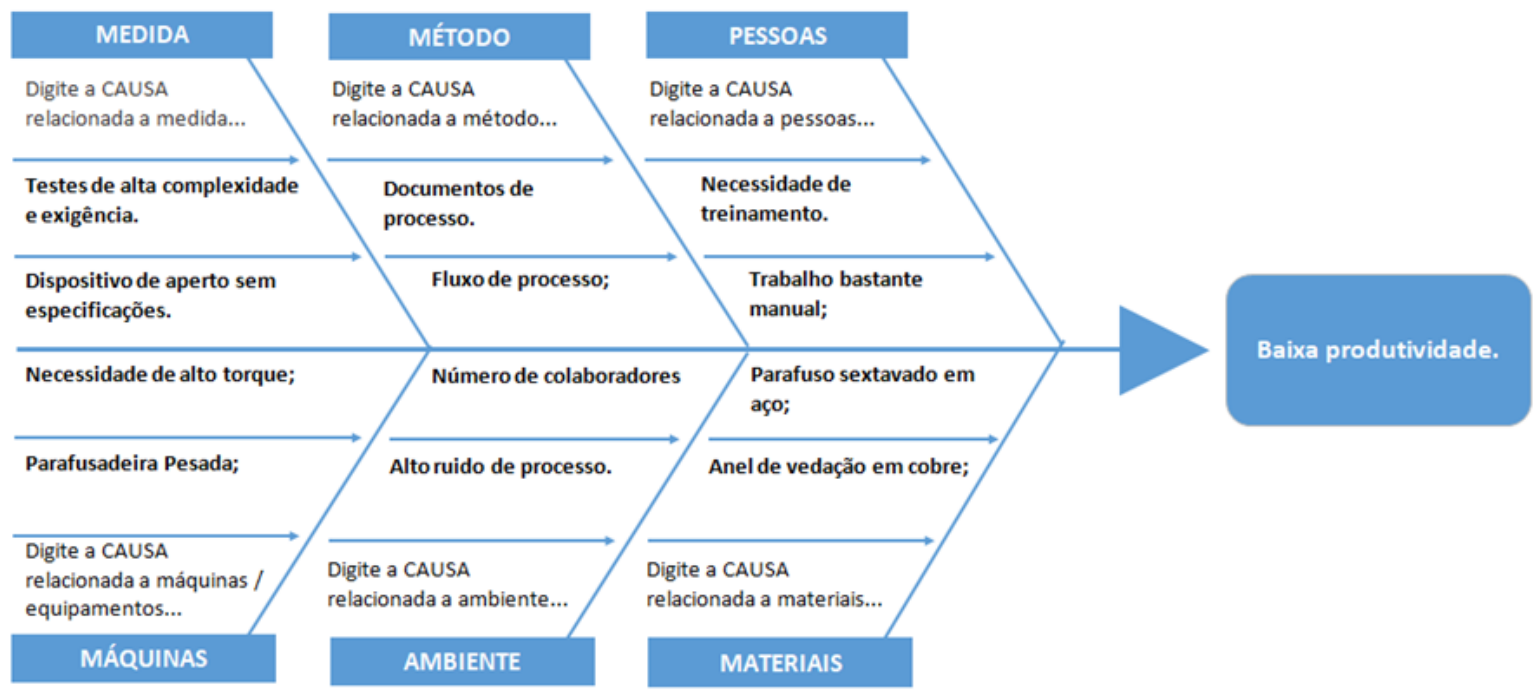

Fonte: Autores (2021).

A Tabela 2 ilustra a matriz GUT elaborada a partir da análise do diagrama de causa e efeito.

Tabela 2 - Matriz GUT

\begin{tabular}{l|c|c|c|c|c}
\hline Matriz GUT & Gravidade & Urgência & Tendência & GxUxT & Classificação \\
\hline Problema & 4 & 4 & 2 & $\mathbf{3 2}$ & $\mathbf{6}^{\circ}$ \\
\hline Trabalho bastante manual & 4 & 4 & 1 & $\mathbf{1 6}$ & $\mathbf{7}^{\circ}$ \\
\hline $\begin{array}{l}\text { Dispositivo de aperto sem } \\
\text { especificação }\end{array}$ & 5 & 4 & 3 & $\mathbf{6 0}$ & $\mathbf{3}^{\circ}$ \\
\hline Necessidade de alto torque & 5 & 5 & 2 & $\mathbf{5 0}$ & $\mathbf{4}^{\circ}$ \\
\hline Parafusadeira pesada & 5 & 5 & 4 & $\mathbf{1 0 0}$ & $\mathbf{2}^{\circ}$ \\
\hline Alto nível de ruído & 5 & 5 & 5 & $\mathbf{1 2 5}$ & $\mathbf{1}^{\circ}$ \\
\hline Anel de vedação em cobre & 4 & 3 & 3 & $\mathbf{3 6}$ & $\mathbf{5}^{\circ}$ \\
\hline Restrição de operadores & & & & \\
\hline
\end{tabular}

Fonte: Autores (2021).

Através da análise das falhas elencadas na matriz GUT foi possível identificar influências sobre o processo e obter as prioridades que deveriam ser revistas para a melhoria do processo de montagem do produto.

Desta forma, após identificação das perdas de vedação, foi realizada uma notificação ao engenheiro de produto da empresa de que o produto apresenta falhas e de que a produção do respectivo item vem apresentando prejuízos no que se refere ao desempenho na montagem do cilindro mestre. A partir disso, foi possível a comunicação dos dados para a melhoria e de um período abastecer o sistema de informações com as sugestões de testes e melhorias. 


\subsection{Definir o plano de ação}

Foi elaborado um plano de ação para a melhoria deste processo, que no primeiro momento dependia do retorno da engenharia de produto para a troca de vedação do produto. Assim, a necessidade de troca do anel de vedação de cobre foi à maior restrição encontrada para solução dos demais problemas.

O engenheiro de produto deliberou pela realização de testes com outros tipos de anéis de vedação. A Tabela 3 apresenta uma matriz de decisão com os três principais anéis, candidatos e já usados no mercado em sistemas de freio tradicional de modo geral.

Tabela 3 - Matriz de decisão

\begin{tabular}{|c|c|c|c|c|c|c|c|}
\hline \multicolumn{2}{|c|}{ Anel de Vedação } & & & & & & \\
\hline Características & Pto & \multicolumn{2}{|c|}{ TOP 2} & \multicolumn{2}{|c|}{ TOP 3} & \multicolumn{2}{|c|}{ TOP 1} \\
\hline Material & 5 & Cobre & 3 & Polímero & 5 & Polímero & 5 \\
\hline Secção & 5 & Retangular & 5 & Transversal & 2 & Retangular & 5 \\
\hline Área de contato & 5 & Grande & 4 & Menor & 2 & Médio & 3 \\
\hline Peso & 5 & Significativo & 3 & Menor & 4 & Menor & 4 \\
\hline Custo & 5 & Elevado & 3 & Baixo & 5 & Baixo & 5 \\
\hline Processo & 5 & Interno & 5 & Comprado & 4 & Interno & 5 \\
\hline TOTAL & 30 & & 23 & & 22 & & 28 \\
\hline
\end{tabular}

Fonte: Autores (2021).

O anel de cobre, TOP2, é o anel de vedação já em uso do produto, ou seja, não necessitando realizar novos testes, já que o indicativo se trata de troca. O anel TOP3 é um anel oring, que garante todas as características e propriedades que são necessárias para a aplicação desejada. Entretanto, ao realizar a montagem e verificar seu desempenho nos testes, notou-se que por apresentar menor área de contato com a superfície de vedação, o mesmo anel se deforma facilmente, apresentando então, maiores chances de rompimento da borracha. Finalmente, os testes realizados com o anel TOP1, demonstraram melhores desempenhos. Houve melhor vedação, pois este anel possui uma secção retangular, ou seja, maior área de contato com a carcaça do produto. Além disso, o modelo de anel TOP1 tem processo de fabricação disponível na organização. 
$\mathrm{O}$ plano de ação $5 \mathrm{~W} 2 \mathrm{H}$ foi elaborado com um checklist de gerenciamento atividades, prazos e responsabilidades necessárias para possibilitar a implementação da melhoria no processo de montagem a partir da troca do anel de vedação de cobre pelo anel TOP1.

O sequenciamento bem-sucedido do plano de ação proposto dependeu bastante da atividade de testes dos cilindros com o novo anel de vedação TOP1. Os resultados obtidos nos testes foram o marco para disparar a melhoria de processo e então implementar o sequenciamento de montagem do item na programação e controle de produção já com as novas mudanças.

\subsection{Agir}

A partir do relatório de aprovação das amostras direcionadas para os testes, foi possível identificar 4 itens importantes e necessário para a implementação de melhorias de processo, sendo eles:

1. Alto nível de ruído gerado na montagem deste cilindro;

2. Necessidade de altos torques para vedação;

3. Peso da parafusadeira em uso;

4. Restrição de operadores.

Todos os 4 itens são relacionados ao maquinário que atendia a montagem do item nas condições anteriores. Foi necessário entrar em contato com diversos fornecedores de parafusadeiras para realizar as etapas de montagem do produto com o novo anel de TOP1.

Seguindo o plano de ação, fez-se necessário 4 meses para o levantamento das novas necessidades de processo, que se tratava de equipamentos que diminuíssem e/ou eliminassem os pontos citados nos 4 itens elencados. A montagem do produto com o anel em borracha passou a exigir um torque de aperto de no máximo $120 \mathrm{Nm}$ de força, da qual foi validada com o auxílio de torquímetro.

Desta maneira foram testados e avaliados outros modelos de parafusadeiras. Ficando definido um equipamento de menor complexidade quando comparado com o maquinário anterior que demandava maiores forças, acarretando maior ruído e peso. 
Assim como a definição do equipamento, houve a remoção de dispositivos da célula de montagem que não se fariam mais necessários. Como exemplo, foi eliminado o balancim, dispositivo que buscava suspender a parafusadeira, já que a mesma era bastante pesada. Passou-se a ter uma nova parafusadeira como peso de $1,1 \mathrm{Kg}$, conforme descrição de fornecimento.

\subsection{Verificar}

O sexto passo do método MASP - PDCA tratou do acompanhamento do processo durante um lote de produção do item em estudo. A Tabela 4 apresenta os dados do lote produzido após a implementação das melhorias de processo. Dados estes obtidos com o acompanhamento de produção deste produto, através de checklist onde pontuamos todas as paradas, dificuldades apresentadase até mesmo aspectos de ganhos, além de toda nova cronoanálise deste fluxo, garantindo os novos dados de produção quantificando a melhoria frente aos números de produção, assim como a busca para evidenciar possíveis problemas e a mudança do fluxo de montagem deste item. Onde não foi constatada a recorrência de falha, indicando o sucesso das ações tomadas.

Seguido o plano de ação, obteve-se a montagem de um lote de produção do item no fim de janeiro, ou seja, com atraso de alguns dias, já que o item demandou de outras operações de produção da empresa.

Tabela 4 - Produção após alteração de processo

\begin{tabular}{r|c|c|c|c|c}
\hline \multirow{2}{*}{2021} & Lote & Quantidade & Reprovações & Anel de vedação & Outros motivos \\
\cline { 2 - 6 } & 1 & 480 peças & 29 peças & 0 peças & 29 peças \\
\hline \multicolumn{2}{r|}{ Total } & 480 peças & 29 peças & \multicolumn{2}{|c}{29 peças } \\
\hline
\end{tabular}

Fonte: Autores adaptado do sistema ERP da empresa (2021).

Os dados apresentados na Tabela 4 mostram o ganho no processo, onde as reprovações identificadas foram provenientes de outros componentes montados inadequadamente, componentes com características de controle de qualidade não conformes e/ou relacionados ao próprio setup de máquina de teste. 


\subsection{Padronizar}

Os passos analisados, assim como as correções necessárias e implementação e verificação das ações foram registradas e documentadas, conforme o sistema de gestão integrada da empresa, fazendo com que as informações chegassem a todos os colaboradores. Ocorreu então a padronização da adequação do sequenciamento de montagem tendo atenção de não acontecer restrição de gênero para a montagem do item e priorizando o balanceamento correto do processo.

Pôde ser definidoo manuseio de um operador para as etapas iniciais, se trata em sua maioria de operadoras mulheres, passando para um operador de montagem final, que pode ser um homem, que fará a finalização do produto. Desta forma encontraremos um sequenciamento linear, sem quebra de fluxo e maior ganho na produção da peça, não havendo mais restrição de gênero no início da montagem.

Foram observadas possíveis dificuldades na montagem e validação da melhoria de produto e processo de montagem. Sendo por exemplo observada a dificuldade de colaboradores não compreenderem no primeiro momento a melhoria proposta no produto e processo. Este fato gerou resistências à colaboração e participação nas mudanças, aspecto notável quando houve a necessidade de coletar assinaturas para aprovações para a mudança.

\subsection{Concluir}

O estudo de caso descrito neste trabalho compreendeu o uso da metodologia de análise e soluções de problemas proposta, tendo como resultado alteração de produto e melhorias no processo de montagem dele.

A aplicação das etapas do MASP- PDCA foi à metodologia utilizada na realização do estudo de caso.

Antes da definição de metodologias, ferramentas e técnicas para a aplicação deste estudo haviam sido feita uma série de testes e investigações a partir de histórico de dados e metodologias mais abertas como a ferramenta de brainstorming. Nota-se também que sem o auxílio das ferramentas dispostas neste estudo, para a obtenção de dados e sua organização, ferramentas estas de qualidade e principalmente da 
metodologia proposta, dificilmente teríamos chegado a conclusões evidentes de identificação, análises e de controle do problema de forma eficiente.

No caso apresentado, buscou-se mostrar o quão eficaz é a metodologia proposta, pois antes havia uma frequência de falha $1 / 5$ peças, que possibilitou chegar a conclusões geradas com os ajustes do item e otimizações do processo, do qual se passou a ter uma frequência aproximada de 1/16 peças de falha, e nenhuma destas devido ao processo alterado, o que tínhamos antes.

\section{DISCUSSÃO DOSRESULTADOS OBTIDOS}

O estudo abordado neste trabalho se mostrou interessante em vários aspectos, já que durante suas análises e mudanças, foi necessária a colaboração de outras pessoas colaboradores nos processos de montagem do produto. O objeto de estudo foi um produto importante e conceituado no mercado da empresa, o que dificultou a adesão dos colaboradores às alterações e melhorias propostas, já que mudanças são vistas como desafios e restrições.

O estudo buscou contemplar adequadamente os conceitos teóricos necessários para o desenvolvimento do estudo de caso. Houve a aplicação de ferramentas da qualidade em cada etapa da realização da metodologia MASP- PDCA. Observou-se a adequação e eficiência dos métodos aplicados, já que foram obtidos resultados satisfatórios para o melhor desempenho do produto em sua linha de montagem na empresa.

A otimização do processo garantiu o ganho de produtividade do produto estudado, que inicialmente se apresentava com produção hora de 33 peças e hoje tem um processo que garante produção hora de no mínimo 40 peças. Assim, consegue-se produzir o lote anual médio do item com 6 horas a menos de produção. O ganho em mão de obra se deu com o fato de encontrarmos um processo de menos complexidade nas condições propostas. Dessa forma, etapas de montagem com exigência de força física, que anteriormente poderiam ser realizadas exclusivamente por colaboradores homens, foram eliminadas ou adaptadas e hoje podem contar com qualquer colaborador da organização. Foi eliminada a restrição de gênero de algumas etapas de montagem do produto já que a nova proposta garante uso de maquinários mais leves, de menor ruído e 
de complexidade de montagem de menor exigência, garantindo assim maior flexibilidade de processo.

Para a validação dos ganhos mencionados, houve o acompanhamento de montagem de lote do produto, validação prevista no plano de ação $5 \mathrm{~W} 2 \mathrm{H}$. O monitoramento se deu por dois turnos de produção, atingindo diferentes operadores, um período de 12 horas de produção, é o que equivale à montagem de 480 peças, das quais apresentaram 29 reprovações, e que por sua vez não apresentaram relação alguma com os aspectos de melhoria dispostos no produto ou com o processo melhorado. $\mathrm{O}$ tempo de ciclo de montagem do item apresentou redução de 20 segundos por item, consequiência de uma montagem mais simples e de menor esforço.

Nas novas condições dispostas foram demonstrados maiores ganhos de lucratividade do produto, pois o fato de elevar a produtividade, acarreta na redução de custos indiretos. Adicionalmente, em se tratando de custos diretos do produto, no que se refere uma produção anual de uma média de 1095 peças, com a mudança de vedação, foi garantido um ganho de $\mathrm{R} \$ 1.598,70$ reais para a organização. Além disso, houve redução de custos através da eliminação da necessidade de pagamento por produção de um item insalubre devido à pressão sonora que antes excedia os níves recomendados.

A Tabela 5 apresenta um comparativo dos ganhos obtidos após a alteração do anel de vedação do cilindro mestre e melhorias implementadas no processo de montagem do produto.

Tabela 5 - Comparativo de ganhos obtidos com a otimização.

\begin{tabular}{l|c|c|l}
\hline Condições & Processo Antigo & Processo proposto & Ganhos \\
\hline $\begin{array}{l}\text { Mão de obra na montagem } \\
\text { do produto }\end{array}$ & Apenas homens & Ambos os sexos & $\begin{array}{l}\text { Quadro } \\
\text { produtivo }\end{array}$ \\
\hline Parafusadeira - Torque & $750 \mathrm{Nm}$ & $140 \mathrm{Nm}$ & Menor impacto \\
\hline Parafusadeira - Peso & $9,8 \mathrm{Kg}$ & $1,1 \mathrm{Kg}$ & $\begin{array}{l}\text { Manuseio } \\
\text { Esforço }\end{array}$ \\
\hline Parafusadeira- Estrutura & Balancim & Não precisa & Flexibilidade \\
\hline Parafusadeira - Ruído & $92 \mathrm{~dB}(\mathrm{~A})$ & $74 \mathrm{~dB}(\mathrm{~A})$ & Ergonômicos \\
\hline Fluxo de processo & Não Sequenciado & Sequenciado & Produtividade \\
\hline Tempo de montagem & Média 110 segundos & Média 90 segundos & Produtividade \\
\hline Custo de produto & Maior & Menor & $\begin{array}{l}\text { Aumento } \\
\text { margem de lucro }\end{array}$ \\
\hline Produtividade & $81 \%$ & $94 \%$ & $13 \%$ de ganho \\
\hline
\end{tabular}

Fonte: Autores (2021).

A análise da Tabela 5 indica que houve ganho de layout de célula, já que passamos a ter uma célula de montagem de menor exigência, sendo eliminado estruturas que antes eram necessárias para a mesma montagem, trazendo flexibilidade para a obtenção deste produto. 


\section{CONTRIBUIÇÕES DA PESQUISA PARA A INDUSTRIA E SOCIEDADE}

Segundo Rebelato et al. (2008) a falta de continuidade e dinamismo interativo na aplicação dos métodos da qualidade pelas empresas é uma realidade. Uma explicação para isso reside no fato de que cada método ou ferramenta foi criado ao seu tempo, por uma organização específica que tinha um problema gerencial pontual e o objetivo de saná-lo. Dessa forma, a aplicação prática em ambiente industrial dos métodos da qualidade ainda é limitada nas indústrias brasileiras, o dificulta a compreensão dos problemas e por consequência ação gerencial para solucioná-los de forma otimizada.

Neste estudo buscou-se aplicar de forma sistemática e integrada métodos da qualidade como MASP-PDCA para identificação e resolução de problema real em uma indústria automotiva. O Gap abordado e solucionado neste trabalho foi conciliar a aplicação sistemática e formalizada de métodos teóricos da qualidade para solução e otimização de um problema real de produção.

Desta forma, o método de pesquisa aplicado no estudo de caso contribui para sociedade, uma vez que a teoria e a prática são aplicadas no ambiente industrial fomentando a cultura da otimização dos processos produtivos e promovendo a divulgação de seus resultados.

\section{CONSIDERAÇÕES FINAIS}

Quando se fala em otimizar processos já se busca pelo processo ideal, ou aquele que chegue mais próximo do desejado. Este ideal, no ramo de autopeças e principalmente na área de frenagem se faz muito importante, já que diariamente contamos com o aumento da concorrência, fato que fomenta a necessidade de processos sob controle e alcance de melhores custos gerados para as empresas, de modo então que permita garantir a qualidade do produto, sem alterar o principio básico de utilização do item. A aplicação de métodos e ferramentas de engenharia de produção para a otimização de um produto automotivo e melhoria de seu processo de montagem foi o objetivo alcançado deste trabalho.

Foram pontuados neste estudo os conceitos dos principais assuntos teóricos como métodos, ferramentas de melhoria de processo. A metodologia de pesquisa do trabalho foi exploratória, aplicada com realização de estudo de caso único e específico. 
Foi realizada a aplicação do método MASP-PDCA no estudo de caso. Oestudo de caso foi realizado com sucesso quanto aos seus objetivos de otimização de produto e melhorias do processo de montagem do cilindro mestre de freio estudado.

Considera-se que, embora a metodologia proposta neste trabalho possa ser aplicada em outros produtos similares da empresa automotiva em estudo, o estudo de caso realizado é único com foco em um produto e, portanto, os resultados obtidos delimitam-se ao escopo deste trabalho específico.

O estudo de caso desenvolvido tratou da otimização do produto cilindro mestre de freio referente ao seu componente de vedação. Através da aplicação do Método de Análise e Solução de Problemas e de diferentes ferramentas da qualidade foi possível obter um ganho de produtividade do produto estudado, que inicialmente se apresentava com produção hora de 33 peças e hoje tem um processo que garante produção hora de no mínimo 40 peças.

A Tabela 5 apresentou os principais resultados obtidos no trabalho.Assim, consegue-se produzir o lote anual médio do item com 6 horas a menos de produção. Neste trabalho foi possível evidenciar a eficiência obtida no processo de montagem do item, relacionando com seu componente de vedação, de modo a não alterar a aplicabilidade do produto, mas aumentar a produção deste, garantindo a durabilidade do cilindro, tornando o item um produto de baixa complexidadee menor perda de montagem. O ambiente de trabalho foi melhorado, uma vez que houve significativa redução de ruído na montagem assim como redução de peso da parafusadeira, minorando o impacto sobre os trabalhadores.

O trabalho realizado foi importante para a empresa. A proposta de melhorias aplicada foi efetiva, além de ter demandado bastante dedicação, assim como a necessidade de parcerias para a finalização. O processo estudado compõe uma cadeia macro e de grande complexidade e demandas, despertando o interesse dos coordenadores e líderes, fomentando como trabalhos futuros a aplicabilidade de estudos semelhantes em outros produtos e componentes automotivos similares da mesma família na empresa. 


\section{REFERÊNCIAS}

ALVES, H. A.; NEVES, A.; CAMPOS, F.; Aplicação da técnica criativa "Brainstorming Clássico" na geração de alternativas na criação de games. Departamento de Design, Universidade Federal de Pernambuco, Pernambuco, Brasil, 2007.

BISOL, M.; Dimensionamento e avaliação experimental de um sistema de freio aplicado a um veículo Baja SAE. Universidade de Caxias do Sul. Caxias do Sul. RS. Brasil, 2021.

BRAGA, N. E; BORGES, F. H.; A utilização da metodologia MASP: Estudo de caso em uma indústria do setor de autopeças automotiva. Conbrepo. Ponta Grossa, PR, Brasil, 2019.

VIANINI, F. M. N.; O estabelecimento das plantas montadoras de veículos no Brasil e na China: o GEIA e os Planos Quinquenais. Universidade Federal de Minas Gerais. Juiz de Fora, MG, Brasil, 2016.

CANO, I.S.; Gerenciamento estratégico e políticas de execução melhoria dos processos. Trabalho de conclusão de curso. Faculdade Carlos Drummond. São Paulo, Brasil, 2006.

DEMING, W. E.; Qualidade: a revolução da administração. Rio de Janeiro: Marques Saraiva, 1986.

DIULGHEROGLO, P. A.; Fundamentos de Freios e seus componentes. Apostila curso. São Paulo: Congresso SAE, 2010.

DNER, Curso para Atualização de Professores em Educação, Vol. 2. Departamento Nacional de Estradas e Rodagens. Rio de Janeiro: MT/DNER, 1983.

LORENZON, E.; DIEDRICH, H.; Utilização do MASP (Método de Análise e Solução de Problemas) em uma granja de suínos. Univates. Lajeado, RS, Brasil, 2019.

FACHIN, O.; Fundamentos de Metodologia. $5^{\text {a }}$ ed. São Paulo: Editora Saraiva, 2006.

GALYÃO, N.; BAZANTE, L.; Aplicação do MASP na solução de problemas de reprocessamento de embalagens de água sanitária. Revista de Engenharia e Pesquisa Aplicada. Recife, Brasil, 2019.

GENERAL SEAL, Anéis de vedações. Disponível em: <https://www.generalseal.com.br/vedacao-epdm> Acesso em: 02 de abril de 2021.

Gil, A. C.; Métodos e Técnicas de Pesquisa Social. 6ª ed. São Paulo: Atlas S.A, 2008.

JÚNIOR, A. M. DE A.; PACHECO, B. C. S.; A redução de custos de refugo por meio da aplicação da metodologia MASP em uma fábrica de sistemas de 
embreagem no interior do estado de São Paulo. Conbrepo. Ponta Grossa, PR, Brasil, 2019.

LIMA, R. G.; Evolução dos motores a combustão interna ciclo Otto no Brasil. Tecnologia em Mecânica Automobilística.Faculdade de tecnologia de Santo André. Santo André, Brasil, 2017.

LOBO, R. S.; LOOS, M. J.; Utilização das ferramentas do MASP para aumento de produtividade de máquina de corte e dobra. Revista GEPROS. Três Lagoas, MS, Brasil, 2017.

MEIRA, R. C.; As ferramentas para a melhoria da qualidade. $2^{\mathrm{a}}$ ed. Porto Alegre: SEBRAE/RS, 2003.

MESQUITA, F. F. DE.; Projeto de um sistema de freio para o veículo de competição off-road - Projeto SAE de mini baja. Universidade Federal do Recôncavo da Bahia. Cruz das Almas, BA, Brasil, 2017.

NASCIMENTO, M. S.; Implantação e evolução da indústria automobilística no Brasil, Revista Tocantinense de Geografia, Araguaína (TO), v. 07, p. 67-79, 2016.

NETO, E. P. P. M.; Projeto e dimensionamento de um sistema de freio aplicado a um protótipo de veículo para competição fora de estrada. Universidade Federal da Paraíba. João Pessoa, PB, Brasil, 2018.

NOVO VAREJO. Jornal de comunicação dirigida ao segmento varejista de autopeças. Disponível em: <https://novovarejo.com.br/executivos-da-reposicaoautomotiva-revelam-expectativas-para-2020> Acesso em: 24 de janeiro de 2021.

OLIVEIRA, S. T.; Ferramentaspara o aprimoramento da qualidade. Colaboração da equipe Grifo. $2^{a}$ ed. São Paulo: Pioneira, 1996.

PESSOAS, R. V. S.; Aplicação do método de análise e solução de problemas no processo de repintura automotiva. Universidade Federal da Grande Dourados. Dourados, MS, Brasil, 2018.

REBELATO, M. G.; FERNANDES, J. M. R.; RODRIGUES, A. M.; Proposta de integração entre métodos para planejamento e controle da qualidade. Revista Gestão Industrial, V. 04, N. 02: p. 162-185, 2008.

SANTO, R.; Brainstorming - Tempestade de ideias (BS - TI) ou Como tirar seu time do "cercadinho mental", Biblioteca temática do empreendedor. São Paulo: SEBRAE, 2015.

SCARTEZINI, L. M. B.; Análise e Melhoria de Processos. Goiânia: Apostila. 54 p., 2009.

SANTOS, G, C, M. DE.; Projeto e dimensionamento de um sistema de freios aplicado a um veiculo de fórmula SAE. Universidade Ferderal do Rio de Janeiro. Rio de Janeiro, RJ, Brasil, 2014. 
SILVA, A. O.; RORATTO, L.; SERVAT, M. E.; DORNELES, L.; POLACINSKI, E., Gestão da qualidade: Aplicação da ferramenta 5W2H como plano de ação para projeto de abertura de uma empresa. Faculdade Horizontina. $3^{\text {a }}$ Semana Internacional das Engenharias da FAHOR, 10 p., 2013.

TERNER, G. L. K.; Avaliação da aplicação dos métodos de análise e solução de problemas em uma empresa metal-mecânica. Universidade Federal do Rio Grande do Sul, Porto Alegre, RS, Brasil, 2008.

UNESP, Matrizde decisão: Universidade estadual Paulista. Disponível em:

$<$ https://acervodigital.unesp.br/bitstream/123456789/65401/11/Matriz\%20de\%20decis \%C3\%A3o.pdf> Acesso em: 08 de abril de 2021.

Recebido em: 15/09/2021

Aprovado em: 15/10/2021

Publicado em: 20/10/2021 